NBER WORKING PAPER SERIES

MEASURING THE EFFICIENCY COST

OF TAXING RISKY CAPITAL INCOME

Roger H. Gordon

John D. Wilson

Working Paper No. 1992

NATIONAL BUREAU OF ECONOMIC RESEARCH 1050 Massachusetts Avenue

Cambridge, MA 02138

August 1986

We would like to thank Ted Bergstrom, Michelle White, participants in seminars at NBER and Michigan, and especially Hal Varian, for helpful discussions. Much of the work on this paper was done while the second author was visiting the University of Wisconsin. The research reported here is part of the NBER's research program in Taxation. Any opinions expressed are those of the authors and not those of the National Bureau of Economic Research. 
Working Paper \#1992

August 1986

Measuring the Efficiency Cost of Taxing Risky Capital Income

$\underline{\text { ABSTRACT }}$

In this paper, we derive a measure of the efficiency cost of taxing risky capital income in an infinite horizon stochastic model. The resulting measure differs from all those that have been proposed in the existing literature. It can be represented by the expression $-\sum_{0} T_{0}^{n} c\left(\Delta X_{0}\right)$, where $T_{0}^{n}$ measures the present value of the taxes that would be paid on a unit of investment in a riskless project with the same expected depreciation rate and tax treatment as capital invested in period $s, X_{0}$, while $c\left(\Delta X_{0}\right)$ represents the certainty equivalent to the representative individual of the lottery $\Delta X_{0}$, where $\Delta X_{0}$ measures the ex post change in investment in period $s$ due to the tax change.

The paper then compares this measure with others that have appeared in the literature. We were unable to find support for the argument in Bulow-Summers(1984) that the efficiency cost of taxing risky capital income is much larger than that implied by the measure $-\sum_{0} T_{\bullet}^{n} E\left(\Delta X_{\bullet}\right)$. In fact, we show in special cases that our measure implies a smaller efficiency cost than does the measure $-\sum_{0} T_{0}^{n} E\left(\Delta X_{0}\right)$.

Roger H. Gordon

Department of Economics

University of Michigan

Ann Arbor, MI 48109
John D. Wilson

Department of Economics

Indiana University

Bloomington, IN 47405 


\title{
MEASURING THE EFFICIENCY COST OF TAXING RISKY CAPITAL INCOMI
}

\author{
by \\ Roger H. Gordon \\ University of Michigan and \\ National Bureau of Economic Research \\ and \\ John D. Wilson \\ Indiana University
}

Many studies in recent years have attempted to measure the efficiency cost of taxing capital income. Doing so is greatly complicated, however, by the importance of risk considerations in capital investment decisions.

Following Harberger (1971), the efficiency cost of any tax change can be measured by $-\sum_{s} T_{s} \Delta X_{s}$, where $T_{s}$ measures the taxes due per unit of the s'th activity, while $\Delta X_{s}$ measures the change in the chosen amount of the $s$ 'th activity due to the tax change. Changes in the amount of the s'th activity affect social welfare to the extent that marginal benefits from the activity differ from marginal costs. But this difference between marginal benefits and costs, externalities aside, equals the per unit tax due on this activity.

Harberger $\mathrm{did}$ not address the question of how to modify this measure when either $T_{s}$ or $\Delta X$, is stochastic. Procedures used in the recent literature for dealing with the effects of risk when measuring the efficiency costs arising from taxes on risky capital income vary widely. Many studies have used the observed average tax payments, $\bar{T}_{s}$, made per unit of the $s$ 'th type of capital to measure the tax distortion discouraging that type of investment. ${ }^{1}$ The efficiency cost of a tax change is then measured by $-\sum_{s} \bar{T}_{s} E\left(\Delta X_{s}\right)$. Here, $E\left(\Delta X_{s}\right)$ represents the expected change in investment due to the tax change. ${ }^{2}$ In contrast, other studies have attempted to estimate the efficiency cost of capital income taxes under the simplifying assumption that the tax distortion on any investment can be measured by that on a riskless investment with the same expected depreciation rate and the same tax treatment. ${ }^{3}$ If $T_{s}^{n}$ measures the taxes that would be paid on a unit invested in such an equivalent but riskless project, and again some procedure is used to forecast $E\left(\Delta X_{s}\right)$, then the measure of the efficiency cost of capital income taxes becomes $-\sum_{s} T_{s}^{n} E\left(\Delta X_{s}\right)$.

1 See, for example, Feldstein(1978) and Fullerton, Shoven, and Whalley (1978). Technically, they measure an average tax rate, then choose parameters such that the resulting before-tax rate of return to capital approximates that observed on average in the data.

2 We will not discuss the procedures used to forecast $E\left(\Delta X_{s}\right)$, and assume that whatever model is used to make these forecasts is consistent with the empirical evidence.

3 See, for example, Fullerton and Gordon (1983) and Slemrod(1983). 
The latter approach typically results in a substantially smaller estimate of the efficiency cost of taxing capital income since for reasonable parameter values $T_{s}^{n}<<\bar{T}_{s}$, for a representative risky project $s$. Investors in the risky project would require a higher expected rate of return (a risk premium) to compensate them for the extra risk that they bear. As a r $; u l t$, when a tax is imposed on the return to capital investments, average tax payments are greater on risky projects since some fraction of this risk premium must also be paid in taxes. ${ }^{4}$ Much of the variation in the estimates of the efficiency cost of corporate taxes reported in recent studies seems to result from this variation in methodology. As a result, some recent studies have reported results using both approaches. ${ }^{5}$

Similar differences exist in theoretical analyses of the appropriate measure of the efficiency cost of taxing risky capital income. For example, the model used by Gordon (1985) implies that the tax distortion arising from a tax on risky capital income would be correctly measured by $-\sum_{s} T_{s}^{n} E\left(\Delta X_{s}\right)$ The basic intuition is that the government, by taxing away some fraction of the income from a project also takes away some fraction of the risk. The gain to investors from no longer bearing as much risk just offsets their loss from paying more taxes on average on a risky project. ${ }^{6}$

Bulow and Summers (1984) claim in contrast that the efficiency cost of taxing capital income is much greater to the extent that this income is risky. They argue that most of the risk in the return on a project is due to random fluctuations in the price of the asset, rather than random fluctuations in the accruing income. Due to the risk in the future asset price, these projects must also earn a larger income to compensate investors for risk. Existing income taxes on risky projects tax away some fraction of this larger income. However, since changes in asset values do not enter into the corporate income tax base, investors must still absorb the entire random fluctuation in the price of the asset. ${ }^{7}$ Therefore, the tax distortion is greater the riskier the project.

Both of these papers use a two period model in which all investment decisions are made in the first period and any random events occur in the second period. This twoperiod framework has several weaknesses. First, the effect of randomness in $\Delta X$, on the measure of efficiency costs cannot be addressed since in a two period model, all investment decisions are made in the first period, before any random event occurs. In addition, it is difficult to treat second period asset prices as market clearing prices - the value of a capital asset at any date should reflect the present value of the future after-tax earnings that would be received from that asset, yet in the second period of a two-period model,

4 For a discussion of some problems with using an average tax rate, even ignoring risk, see Auerbach (1984).

5 See, for example, Galper, Lucke, and Toder(1985).

6 This paper assumes that the cost to the government of bearing risk is the same as that faced by private investors. To the extent that the government can bear risk more cheaply than private investors, there is an efficiency gain from taxing risky capital income. For further discussion, see Tobin (1958) or Stiglitz (1969).

7 Only to the extent that there are capital gains taxes does the government absorb any risk in their argument. 
there are no future earnings. Given this problem, Bulow-Summers assume that second period asset prices are exogenous, and so assume away any link between the tax law and the discounted present value of future after-tax income. The objective of this paper is to analyze the efficiency costs of taxing risky capital income in an infinite horizon model in which both the income earned on capital and the market value of existing capital fluctuate randomly over time. We will then compare this measure with the measures derived in a two-period setting, and also with those measures used in empirical studies.

Our first main conclusion is that the stochastic properties of the $\Delta X$ s play a key role in the measure of the efficiency cost of capital income taxes. If the amount invested in each capital project were nonstochastic, then the efficiency cost of changing the capital income tax would be correctly measured by $-\sum_{s} T_{s}^{n} E\left(\Delta X_{s}\right)$. In general, however, future investment rates, and the effect of the tax law on future investment rates, are stochastic since they are based on future information. When they are, the efficiency cost of changing the capital income tax would be measured by $-\sum_{s} T_{s}^{n} c\left(\Delta X_{s}\right)$, where $c\left(\Delta X_{s}\right)$ is the certainty equivalent of the lottery $\Delta X_{s}$.

This measure of the efficiency cost of capital income taxes in principle can be either larger or smaller than that produced using the measure $-\sum_{s} T_{s}^{n} E\left(\Delta X_{s}\right)$, the type of measure used in the empirical studies by Fullerton-Gordon (1983) and Slemrod(1983). Determining the relative size of these two measures of the efficiency cost is extremely difficult except in very special cases. For example, if there were no risk in asset values, only in asset income, then taxing capital income would in fact be less costly than is suggested using the measure $-\sum_{s} T_{s}^{n} E\left(\Delta X_{s}\right)$. While we argue intuitively that the efficiency cost of capital income taxes should normally be smaller than is implied by the measure $-\sum_{s} T_{s}^{n} E\left(\Delta X_{s}\right)$, definitive results await further theoretical work and simulation studies.

Finally, we find that the efficiency cost of taxing corporate income should be less if the tax allows ex post depreciation as a deduction rather than ex ante expected depreciation. However, this result is clear only under a set of assumptions which imply that the efficiency cost of a tax which allows ex ante expected depreciation as a deduction is overestimated by the expression $-\sum_{s} T_{s}^{n} E\left(\Delta X_{s}\right)$.

The organization of the paper is as follows. In the first section, we describe the assumptions used in the model. In section 2, we derive a measure of the efficiency cost of a permanent increase in the tax rate on capital income assuming the style of corporate tax currently used in the U.S. This measure of the efficiency cost of corporate income taxation is then compared in section 3 with those used in earlier papers. In section 4 , we derive a measure of the efficiency cost of corporate taxation under the assumption that the tax law uses economic depreciation, basing the depreciation deduction on the ex post change in asset values. Finally, in section 5 we summarize the main results. 


\section{Structure of the model}

For simplicity of notation, we assume that there is one firm in the economy, which behaves competitively. ${ }^{8}$ If this firm has a capital stock $K_{t}$ at the beginning of any given period $t$, then its actual income from capital during the period is $\theta_{t} f\left(K_{t}\right)$, where the function $f($.$) satisfies the normal properties of a production function, and where \theta_{t}$ is a random variable whose probability distribution is left arbitrary. This income from capital is subject to corporate taxes at rate $\tau$, leaving an after-tax income of $(1-\tau) \theta_{t} f\left(K_{t}\right)$. We assume here that the tax law allows full loss-offset.

Each period, capital is subject to a random proportional depreciation rate $\delta_{t}$, so that the capital stock remaining at the end of period $t$ is only $\left(1-\delta_{t}\right) K_{t}$. The firm can add to its capital stock each period, but faces convex adjustment costs when it does so. If the firm were to add $N_{t}$ to its capital stock in period $t$, the cost of doing so would be $q_{t}\left(N_{t} ; \phi_{t}\right)$, where $q_{t}(0)=0, q_{t}^{\prime}>0$, and $q_{t}^{\prime \prime}>0$. Here, $\phi_{t}$ represents other random factors which may affect the size of these adjustment costs. This type of specification of the cost of additions to the capital stock has been used extensively in recent papers. ${ }^{9}$ if the chosen amount of new investment is $N_{t}$, then the firm's capital stock in period $t+1$ would equal ${ }^{10}$

$$
K_{t+1}=\left(1-\delta_{t}\right) K_{t}+N_{t}=\sum_{s=0}^{\infty} N_{t-s} \Pi_{v=1}^{s}\left(1-\delta_{t-v}\right)
$$

Under current tax law, whenever a firm undertakes new investment, it accrues the right to a stream of depreciation deductions from its taxable income, and perhaps also to an investment tax credit. To capture the economic effects of such deductions, we assume that the firm can deduct $z q_{t}$ from its taxable income in the period of the investment, implying that the after-tax cost of adding $N_{t}$ to the capital stock would be $(1-\tau z) q_{t}{ }^{11}$ For simplicity, we assume that the value of $z$ does not change over time, and that $z<1$.

8 All our results concerning efficiency costs generalize trivially if we allow for many firms, simply requiring a sum across firms.

${ }^{9}$ See, for example, Summers (1981), Abel (1980), or Hayashi (1982).

10 In equation (1) and throughout the paper, we adopt the convention that $\prod_{v=i}^{i-1}(1-$ $\left.\delta_{t-v}\right)=1$.

11 The term $r z$ is intended to measure the present-value of whatever tax savings result under existing law from undertaking a unit of investment, so would equal the tax credit rate plus $\tau$ times the present-value of depreciation deductions. Since depreciation deductions are normally risk-free in nominal terms, the appropriate discount rate would simply be the after-tax interest rate on nominally risk-free securities. We assume in the model that the tax savings occur immediately to simplify the discussion concerning the use of the tax revenue. 
We also assume that there is a representative consumer who lives forever. His objective function in period $t, W_{t}$, is assumed to equal.

$$
W_{t}=E_{t} \sum_{s=t}^{\infty} \beta^{s-t} U\left(C_{s}\right)
$$

where $C_{s}$ is consumption in period $s$, where $\beta$ is the discount factor for future utility, and where the expression $E_{t}$ is the expectations operator based on information available when decisions are made in period $t$. The consumption good is assumed to be the numeraire, and so its price remains constant over time. All values and rates of return therefore represent real rather than nominal figures.

In each period $s$, our representative consumer receives income from any financial securities that he owns, receives some exogenous income, $w_{*}$, which is also stochastic, and receives a perhaps stochastic lump-sum transfer from the government of $L_{\mathbb{*}}$. He then chooses how much to consume that period and how much to invest in each of the available securities so as to maximize expected utility. Each period the individual can invest in risky physical capital in each of the firms and also in riskless bonds of any maturity. We assume that these bonds are pure discount bonds - a bond of maturity $n$ in period $s$ pays a unit of real goods in period $s+n$ and sells in period $s$ for $R_{s n} \cdot{ }^{12}$ Let the individual's holdings of bonds in period $s$ of maturity $n$ be denoted by $B_{s n}$. The aggregate supply of such bonds in the economy is assumed to be zero, so that in equilibrium the $R_{s n}$ must adjust so that $B_{s n}=0.13$

The representative individual's budget constraint in period $s$ is therefore

$$
C_{s}=w_{s}+\sum_{n} R_{s n}\left(B_{s-1, n+1}-B_{s n}\right)+(1-\tau) \theta_{s} f\left(K_{s}\right)-(1-\tau z) q_{s}\left(N_{s}\right)+L_{s}
$$

Each period, he must choose how much to invest in bonds of each maturity and in new capital, subject to this budget constraint, so as to maximize expected utility. The firstorder condition characterizing optimal bond holdings of maturity $n$ in period $t$ can be expressed as

$$
R_{t n} U_{t}^{\prime}=E_{t} U_{t+n}^{\prime}
$$

12 The objective here is simply to define the real risk free rate at which goods can be traded between any two time periods. Such a rate implicitly exists no matter what the characteristics of actual securities are.

13 Except when noted, our expressions for the efficiency cost of tax changes are identical under the alternative assumption that the country can borrow and lend without limit internationally at some fixed interest rates. 
Similarly, the first rerder conditions for the optimal investment in the firm's capital stock in period $t$ can be expressed, using equation (1), as: ${ }^{14}$

$$
q_{t}^{\prime}(1-\tau z) U_{t}^{\prime}=(1-\tau) E_{t} \sum_{s=1}^{\infty}\left[\Pi_{v=2}^{s}\left(1-\delta_{t+v}\right)\right] \theta_{t+s} f_{t+s}^{\prime} \beta^{s} U_{t+s}^{\prime} .
$$

This equation can also be expressed as:

$$
(1-\tau z) q_{t}^{\prime} U_{t}^{\prime}=E_{t} \beta U_{t+1}^{\prime}\left[(1-\tau) \theta_{t+1} f_{t+1}^{\prime}+(1-\tau z)\left(1-\delta_{t+1}\right) q_{t+1}^{\prime}\right]
$$

\section{Welfare costs of tax changes}

In analyzing the welfare effects of taxing capital income, we assume that the revenue received from the tax on capital income is returned in a lump sum fashion to individuals. We do this, not because this is a realistic policy option, but in order to avoid obscuring the measure of the welfare cost of changing the tax rate on capital income with any welfare effects arising from how the extra tax revenue is used. Similarly, we assume that there are no other taxes in use, so that no second best welfare effects arise due to changing demands for other taxed activitics. Adding these complications would be straight-forward, but would again obscure the analysis. equals

Government tax revenue, $G_{s}$, collected in period $s$ from the representative individual,

$$
G_{s}=\tau\left[\theta_{s} f\left(K_{s}\right)-z q_{s}\left(N_{s}\right)\right] \text {. }
$$

By assumption, $L_{s}=G_{s}$.

In measuring the welfare costs of permanent tax changes introduced in the initial period $t=0$, we simply use the representative individual's welfare measure, $W_{t}$. Differentiating $W_{t}$ with respect to $\tau$, allowing $L_{s}$ to readjust appropriately in each period $s$, we find that

Proposition 1: The effect on welfare of a permanent marginal increase in $\tau$, the tax rate on capital income, enacted in the initial period, equals

$$
\frac{\partial W_{0}}{\partial \tau}=\frac{\tau(1-z)}{(1-\tau)} \sum_{s=0}^{\infty} \beta^{s} E_{0} U_{s}^{\prime} q_{s}^{\prime} \frac{\partial N_{s}}{\partial \tau} .
$$

14 We assume throughout the paper that equations ( $5 \mathrm{ab}$ ) always hold with equality, so assume that any constraint that $N_{t}>0$ is nonbinding. Note that due to depreciation of existing capital, the capital stock can still be reduced even when the gross investment rate, $N_{t}$, is positive. 
Proof: Differentiating the welfare measure of the representative individual with respect to $\tau$, and using the first order conditions to eliminate any direct effects of behavioral responses on welfare, given the $L_{s}$, we find that

$$
\frac{\partial W_{0}}{\partial \tau}=E_{0} \sum_{s=0}^{\infty} \frac{\partial N_{s}}{\partial \tau}\left\{\sum_{n=s+1}^{\infty}\left[\beta^{n} U_{n}^{\prime} \tau\left(\Pi_{v=s+2}^{n}\left(1-\delta_{v}\right)\right) \theta_{n} f_{n}^{\prime}\right]-\tau z q_{s}^{\prime} \beta^{s} U_{s}^{\prime}\right\} \text {. }
$$

Using equation (5a) to reexpress the first term in equation (8), and simplifying, immediately gives the result stated in the proposition.

We find in the proposition that the marginal welfare loss from an increase in $\tau$ consists of a sum of expressions each containing a tax term multiplied by a change in behavior. It therefore corresponds to the measure, ${ }^{15}-\sum_{s} T \Delta X_{s}$, derived in Harberger (1971) for a marginal welfare loss from a tax change. In our context, this measure of the welfare loss is stochastic, however, and the loss that would occur under each possible contingency must be weighted by $t \therefore$ marginal utility of income under that contingency.

This measure of the marginal welfare loss from tax changes differs from each of the measures that have been commonly used in the literature. The past literature has focussed on how to revise the measure of the tax distortion term in Harberger's welfare loss measure to account for the effects of uncertainty. Proposition 1 shows that this has not been the right focus. In equation ( 7$)$, the tax parameter, $\tau(1-z) /(1-\tau)$, which measures the size of the tax distortion, is unaffected by any of the sources of uncertainty. This term in fact simply equals the market value of the taxes collected on a unit of investment in physical capital, measured in consumption units as of the date the investment is made. To see this, note that the utility loss from the taxes paid on the income from a unit of capital investment in period $t$ would equal

$$
-\tau z q_{t}^{\prime} U_{t}^{\prime}+\tau \sum_{s=t+1}^{\infty} \beta^{s-t} U_{s}^{\prime} \theta_{s} f_{s}^{\prime}\left[\Pi_{v=t+2}^{s}\left(1-\delta_{v}\right)\right] .
$$

Using equation (5a) to substitute for the second term, and simplifying, gives $U_{t}^{\prime} q_{t}^{\prime} \tau(1-$ $z) /(1-\tau)$. To measure the tax loss from a unit of new investment, we must divide by $q_{t}^{\prime}$, and to reexpress this in consumption units in period $t$ we must divide again by $U_{t}^{\prime}$, yielding the tax distortion measure that appears in proposition $1 .{ }^{16}$ Therefore, the market

15 Equation (7) describes a measure of the welfare gain from a tax increase, so the welfare loss has the opposite sign.

16 This measure of the present value of tax payments from a dollar of new investment is the same as would be derived using the more standard Hall-J irgenson (1967) approach. In their model, but using our notation, a dollar of new investment must earn a before tax return each period of $(r+\delta)(1-\tau z) /(1-\tau)$. The taxes that would be paid on this return each period would equal $(\tau+\delta)(1-\tau z) /(1-\tau)-(r+\delta)=\tau(1-z)(r+\delta) /(1-\tau)$. But an initial investment of a dollar implies an extra amount of capital $t$ periods later of $(1-\delta)^{t}$. The present value of tax payments resulting from a dollar of new investment therefore equals $[\tau(1-z)(r+\delta) /(1-\tau)] \sum_{t}(1-\delta)^{t}(1+r)^{-t}=\tau(1-z) /(1-\tau)$. 
value of the taxes paid on a unit of new investment is unaffcted by the riskiness of the project, and can be measured most easily by taking the present value of the taxes paid on a risk-free project, discounted to the present using the risk-free interest rate.

Proposition 1 shows, however, that uncertainty in the behavioral response to a tax change, $q_{s}^{\prime} \partial N_{s} / \partial \tau$, does complicate the measure of the welfare loss. To isolate the effects of this uncertainty on the measure of the welfare loss, it is useful to derive the following result.

Corollary 1: The effect on welfare of a permanent marginal increase in $\tau$, the tax rate on capital income, enacted in the initial period, also equals

$$
\frac{\partial W_{0}}{\partial \tau}=U_{0}^{\prime} \frac{\tau(1-z)}{(1-\tau)}\left[\sum_{s=0}^{\infty} R_{0, s} E_{0} q_{s}^{\prime} \frac{\partial N_{s}}{\partial \tau}+\sum_{s=0}^{\infty} \beta^{s} \operatorname{cov}\left(U_{s}^{\prime}, q_{s}^{\prime} \frac{\partial N_{s}}{\partial \tau}\right)\right] \text {. }
$$

Proof: Substituting the identity

$$
q_{s}^{\prime} \partial N_{s} / \partial \tau=E_{0}\left(q_{s}^{\prime} \partial N_{s} / \partial \tau\right)+\left[q_{s}^{\prime} \partial N_{s} / \partial \tau-E_{0}\left(q_{\theta}^{\prime} \partial N_{s} / \partial \tau\right)\right]
$$

into equation ( 7 ) gives

$$
\frac{\partial W_{0}}{\partial \tau}=\frac{\tau(1-z)}{(1-\tau)}\left[\sum_{s=0}^{\infty} \beta^{s} E_{0}\left(U_{s}^{\prime}\right) E_{0}\left(q_{s}^{\prime} \frac{\partial N_{s}}{\partial \tau}\right)+\sum_{s=0}^{\infty} \beta^{s} \operatorname{cov}\left(U_{s}^{\prime}, q_{s}^{\prime} \frac{\partial N_{s}}{\partial \tau}\right)\right] .
$$

Using equation (4) to substitute for $\beta^{\circ} E_{0} U^{\prime}$ immediately gives the desired result.

In this corollary, we decompose the efficiency cost of a tax change into two terms. We will examine each in turn.

The first term corresponds directly to the measure $-\sum_{s} T_{s}^{n} E\left(\Delta X_{s}\right)$, and would have exactly the same form in a nonstochastic model. Here, $T_{s}^{n}$ equals the present value of the taxes paid on a dollar of new (risk-free) investment made in period $s$, discounted back to the present at the risk-free rate, while $E\left(\Delta X_{s}\right)$ measures the expected change in the dollar amount of new investment in period $s$.

The second term in equation (10) describes how the measure of the efficiency cost of a tax change differs in form due to the presence of risk. It is nonzero only to the degree that the tax change leads to a stochastic change in the value of capital investment which is correlated with the stochastic value of the marginal utility of income. The ex post measure of the efficiency cost of a tax increase due to revised decisions in period $s$ is $-T_{s}^{n} \Delta X_{s}$. If the loss is large when the individual can least afford it, then the certainty equivalent of the loss is underestimated by its expected value, and conversely. Since future investment decisions will be based on information available in the future but not known now, these decisions will be stochastic given today's information. This randomness in future investment decisions could result from any source of uncertainty, such as randomness in other sources of income, 
and not just from randomness in the return to new investments. Therefore, this term should be nonzero even for investments in risk-free projects, since the amount invested in such projects in future periods, and the response of this investment rate to tax changes, will depend on future events.

In a two period model, the behavioral response to a tax change is nonstochastic, since it occurs before any new information is revealed. Therefore, measures of the efficiency cost derived in a two period model, such as in Gordon (1985), would omit this second term in equation (10).

It is difficult to say anything in general even about the sign of this second term, let alone its size. In order to shed some light on the factors which influence the sign of this term, we will examine a very special case. In particular, assume that: (A1) $U\left(C_{t}\right)=$ $C_{t}^{1-\gamma} /(1-\gamma)$, (A2) $f\left(K_{t}\right)=m K_{t}$, (A3) $w_{t}=0$, (A4) $q_{t}\left(K_{t}\right)=K_{t}$, and (A5) $\theta_{t}$ and $\delta_{t}$ are each iid. This particular set of assumptions is one of the few examples in which analytical solutions exist for optimal behavior in an infinite horizon stochastic model. ${ }^{17}$ Given these assumptions there are two sources of uncertainty left $-\theta_{t}$ and $\delta_{t}-$ and each has different effects on the size of the second term in equation (7). If we ignore uncertainty in $\delta_{t}$, and so assume that $(\mathrm{A} 6) \delta_{t}$ is nonstochastic, then we can prove the following result.

Proposition 2a: Given assumptions (A1) - (A6), it follows that

$$
\operatorname{cov}\left(U_{s}, \partial N_{s} / \partial \tau\right)>0
$$

Proof: See the appendix.

Therefore, if the only source of uncertainty is in the annual earnings from capital, then the covariance term must be positive and the true welfare cost of increasing the corporate tax rate is less than that forecast using an expression of the form $-\sum_{s} T_{s}^{n} E\left(\Delta X_{s}\right)$. The intuition underlying this result might be explained as follows. Whenever a favorable outcome for $\theta_{t}$ occurs, the individual will divide this windfall between extra current consumption and extra savings which finances further capital investment. Under the above assumptions, $\partial N_{s} / \partial \tau=-a K_{s}$ for some constant $a$. Therefore, when the desired capital stock is large, due to a favorable outcome of $\theta_{t}$, the drop in investment due to a tax increase would also be large. Therefore the behavioral response is greatest in just those states when the individual can best afford it, implying that in the presence of uncertainty the welfare loss from a tax increase would be overestimated by the measure $-\sum_{s} T_{s}^{n} E\left(\Delta X_{s}\right) \cdot{ }^{18}$

If instead the only uncertainty is in $\delta_{t}$, so that we replace (A6) with (A7) $\theta_{t}=1$, then we find the following.

17 In analyzing this model, we do make use of the assumption that the economy is closed.

18 It is easy to show in this example that welfare still drops due to a tax increase as long as the gross investment rate is positive. 
Proposition 2b: Given assumptions (A1) - (A5) plus assumption (A7), then if $\tau$ is increased in period 0 it follows that $\operatorname{cov}\left(U_{s}^{\prime}, \partial N_{s} / \partial \tau\right)>0$ if $\alpha>s /(1+s)$, where $\alpha=K_{s+1} /\left(C_{s}+K_{s+1}\right) .^{19}$

Proof: See the appendix.

Since $\alpha<1$, it must be that $\alpha<s /(1+s)$ for large enough values of $s$. However, it does not necessarily follow that the covariance is negative when $\alpha<s /(1+s)$. In the proof, we show that $U_{s}^{\prime}$ and $\partial N_{s} / \partial \tau$ are positively correlated due to all random events that have occurred from date 1 to date $s-1$, but are negatively correlated due to the random event at date $s$ when $\alpha<s /(1+s)$ and conversely. Therefore, it is difficult to say anything in general about the sign of the second term in equation (7) when the source of the uncertainty is a random $\delta$.

The intuitive reason why this case is more complicated can be described as follows. As before, when past luck has been unfavorable, the individual will choose both to consume less and to maintain a smaller capital stock. Under our assumptions, the drop in the size of the desired capital stock due to a tax increase is proportional to the size of the capital stock, so is small when the capital stock is small. This implies a positive covariance between $U_{s}^{\prime}$ and $\partial N_{s} / \partial \tau$. In addition, however, when $\delta_{s}$ is large, the capital stock is unexpectedly smaller and new investment is needed to replace what was lost. When taxes are increased, less capital would have been present to begin with, so the amount of capital that needs to be replaced is less. Taken by itself, this factor suggests a negative covariance between $U_{s}^{\prime}$ and $\partial N_{s} / \partial \tau$.

If the only uncertainty were exogenous movements in $q_{t}$, so that $q_{t}$ depended on $\phi_{t}$ but not $N_{t}$, then a similar result to proposition $2 \mathrm{~b}$ can be proven. Neither of these cases, however, provides a very appealing model of the underlying source of asset price volatility since in both these examples the market value of the existing capital stock and the rate of new investment will be negatively correlated, contrary to the evidence in Abel (1980) or Summers (1981).

We have not been able to prove anything in general about the sign of this term, let alone its size. Simulation studies would probably be useful, and we are in the process of attempting them. We do expect, however, that with reasonable parameter values this term will turn out to be positive. Consider first the effects of an unexpected increase in income in some period $t$. This would certainly cause the value of $U_{t}^{\prime}$ to fall. Also, as long as the investor has decreasing absolute risk aversion, investment in risky capital should be higher. For this second term to be positive, all that is needed in addition is that the drop in investment expenditures due to taxes be greater under those contingencies when the investment rate is greater. It is hard to come up with circumstances when this would not be true.

19 See the appendix for a demonstration that $\alpha$ does not vary over time under our assumptions. 
If the random event is an increase in the expected rate of return on future investment, rather than an unexpected increase in income, and if the economy is open and faces an exogenous world interest rate, then again the value of $U_{t}^{\prime}$ should fall. The investment rate in risky capital would certainly rise, and again the covariance would be positive as long as the drop in investment due to taxes is larger when the investment rate is larger. ${ }^{20}$

Finally, if we consider past random events which lead to a larger inherited capital stock, current consumption will certainly be higher, and the value of $U_{t}^{\prime}$ lower. In addition, we would normally expect the current investment rate to be higher - not only is there more capital to be maintained but also the same random outcomes which made past investment more attractive presumably continue to make new investment attractive. If so, then the covariance would be positive as long as the drop in investment due to taxes is larger when the investment rate is larger.

\section{Comparison with other measures of the marginal welfare loss}

In order to compare the measure of the efficiency cost of a tax increase derived here with those used in previous studies, we run into the problem that much of the past literature follows the Hall-Jorgenson (1967) approach and assumes myopic expectations when modelling investment behavior. In order to make our model more comparable, we now make the following additional assumptions: (B1) the depreciation rate is nonstochastic and constant over time for each firm, (B2) the economy is open and can borrow and lend freely at a constant risk-free world interest rate $r$, and (B3) there is no international trade in risky securities.

Given these assumptions, we prove the following corollary:

Corollary 2: Given assumptions (B1)-(B9), the effect on welfare of a permanent marginal increase in $\tau$, enacted in the initial period, also equals

$$
\begin{aligned}
\frac{\partial W_{0}}{\partial \tau}=\frac{\tau(1-z)}{(1-\tau)} & {\left[(r+\delta) U_{0}^{\prime} E_{0} \sum_{s=1}^{\infty}(1+r)^{-s} q_{s-1}^{\prime} \frac{\partial K_{s}}{\partial \tau}\right.} \\
+ & (1-\delta) U_{0}^{\prime} E_{0} \sum_{s=1}^{\infty}(1+r)^{-s}\left(q_{s-1}^{\prime}-q_{s}^{\prime}\right) \frac{\partial K_{s}}{\partial \tau} \\
+ & \left.\sum_{s=1}^{\infty} \beta^{s} \operatorname{cov}\left(U_{s}^{\prime}, q_{s}^{\prime} \frac{\partial N_{s}}{\partial \tau}\right)\right] .
\end{aligned}
$$

Proof: Substituting the identity $\partial N_{s} / \partial \tau=\partial K_{\diamond}+1 / \partial \tau-(1-\delta) \partial K_{\diamond} / \partial \tau$ into equation (10) and simplifying yields the desired result.

${ }^{20}$ In a closed economy, however, an increase in the expected rate of return to future investment would likely lead to an increase in savings and therefore a rise in $U_{t}^{\prime}$, so results may reverse. 
In this corollary, we decompose the same measure of the efficiency cost of a tax change into three terms. The first term again corresponds in form to the Harberger measure, $-\sum T_{s}^{n} E \Delta X_{s}$, and is almost exactly the measure of the efficiency cost used in FullertonGordon (1983) and Slemrod(1983). Here, $T_{o}^{n}$ now equals the taxes due each period on the income earned from a dollar invested in a risk-free project, ${ }^{21}$ discounted to the present at the risk-free rate, while $E \Delta X_{s}$ equals the change in the dollar value of the capital in place in period $s$ due to the tax change. ${ }^{22}$

These papers ignore the last two terms in equation (13). The last term we have already discussed. The second term captures the effects of expected changes in asset prices on the tax distortion. The same type of term would appear in a nonstochastic model when asset prices are expected to change. ${ }^{23}$ Past studies of efficiency costs have ignored any expected changes in asset prices. If in fact asset prices are expected to fall in the future, as perhaps would be the case for particular assets such as computers, then the efficiency cost of a tax increase would be greater.

A number of other studies, e.g. Fullerton, Shoven, and Whalley (1978), also measure the efficiency cost of tax changes by a term closely corresponding to the first term in equation (13), except that they measure the tax parameter by the average taxes paid per period by a typical project, rather than by the taxes that would have been paid by an equivalent but riskless project. If our intuition is right that the last term in equation (13) is positive, and if we ignore the second term in the equation, then these studies should substantially overestimate the efficiency costs of taxing risky capital income.

In order to discuss the nature of the argument in Bulow and Summers (1984), it is useful to prove the following proposition:

Proposition 3: The effect on welfare of a permanent marginal increase in $\tau$, enacted in the initial period, equals

$$
\frac{\partial W_{0}}{\partial \tau}=E_{0} \sum_{s=1}^{\infty} T_{s} \beta^{s} U_{s}^{\prime} \frac{\partial K_{s+1}}{\partial \tau}
$$

where

$$
T_{s}=\frac{\tau(1-z)}{1-\tau}\left\{\frac{q_{s}^{\prime}(r+\delta)}{1+r}+\beta(1-\delta) \frac{\left(q_{s}^{\prime}-q_{s+1}^{\prime}\right) U_{s+1}^{\prime}}{U_{s}^{\prime}}\right\}
$$

21 Given the tax law, a dollar invested in a risk-free project must earn a rate of return $(r+\delta)(1-\tau z) /(1-\tau)$, and therefore must pay in taxes each year $(r+\delta)(1-\tau z) /(1-\tau)-$ $(r+\delta)=\tau(1-z)(r+\delta) /(1-\tau)$.

22 These past papers, however, used a nonstochastic model to forecast $E \Delta X_{8}$, and try to forecast $E \partial K / \partial \tau$, rather than $E q^{\prime} \partial K / \partial \tau$. Note that $E\left(q^{\prime} \partial K / \partial \tau\right) \neq E\left(q^{\prime}\right) E(\partial K / \partial \tau)$.

23 When assets prices are expected to change, the required rate of return on a dollar invested in a risk free project would be $\left(q^{\prime}(r+\delta)-(1-\delta) \Delta q^{\prime}\right)(1-\tau z) /(1-\tau)$ and the annual tax payments would be $\left(q^{\prime}(r+\delta)-(1-\delta) \Delta q^{\prime}\right)(1-\tau z) /(1-\tau)-\left[(r+\delta)-\Delta q^{\prime}\right]=$ $\tau(1-z)\left[q^{\prime}(r+\delta)-(1-\delta) \Delta q^{\prime}\right] /(1-\tau)$. 
Proof: Differentiating the representative individual's welfare with respect to $\tau$, using equation (1) to substitute for $N_{s}$, gives

$$
\frac{\partial W_{0}}{\partial \tau}=E_{0} \sum_{s=1}^{\infty}\left[\left(\tau \theta_{s} f_{s}^{\prime}+q_{s}^{\prime} \tau z(1-\delta)\right) \beta^{s} U_{s}^{\prime}-q_{s-1}^{\prime} \tau z \beta^{s-1} U_{s-1}^{\prime}\right] \frac{\partial K_{s}}{\partial \tau} .
$$

Using equation (5b) to reexpress the first term, and simplifying, gives

$$
\frac{\partial W_{0}}{\partial \tau}=\sum_{s=1}^{\infty} \frac{\tau(1-z)}{(1-\tau)} E_{0}\left[q_{s-1}^{\prime} \beta^{s-1} U_{s-1}^{\prime}-q_{s}^{\prime}(1-\delta) \beta^{s} U_{s}^{\prime}\right] \frac{\partial K_{s}}{\partial \tau} .
$$

Substituting the identity $q_{s}^{\prime}=q_{s-1}^{\prime}+\left(q_{s}^{\prime}-q_{s-1}^{\prime}\right)$, using equation (4), and simplifying yields the desired result.

In this proposition, the term $T$ measures the tax distortion affecting decisions made that period about the size of the capital stock available for production the following period. The first term of $T_{0}$ is exactly what would be calculated in a certainty model which ignored asset price changes, while the second term describes the effects of asset price changes on the size of the tax distortion. If prices are rising, then capital need not earn as much income to remain attractive. Since only the income, and not the capital gain due to the price rise, is taxable, rising prices result in a smaller tax distortion.

Since Bulow and Summers examined a two period model, they focussed solely on behavioral responses in the first period. If we focus on just the first term in equation (14), when $s=0$, we find that

$$
\begin{aligned}
\frac{\partial W_{0}^{B S}}{\partial \tau}= & \frac{\tau(1-z)}{(1-\tau)}\left[(r+\delta) U_{0}^{\prime} E_{0}(1+r)^{-1} q_{0}^{\prime} \frac{\partial K_{1}}{\partial \tau}\right. \\
& +(1-\delta) U_{0}^{\prime} E_{0}(1+r)^{-1}\left(q_{0}^{\prime}-q_{1}^{\prime}\right) \frac{\partial K_{1}}{\partial \tau} \\
& \left.\quad-(1-\delta) \beta \operatorname{cov}\left(U_{1}^{\prime}, q_{1}^{\prime} \frac{\partial K_{1}}{\partial \tau}\right)\right], \\
= & \frac{\tau(1-z)}{(1-\tau)} \beta E_{0} U_{1}^{\prime} \theta_{1} f_{1}^{\prime} .
\end{aligned}
$$

The last line follows immediately from equation $(5 \mathrm{~b})$. The resulting measure of the welfare loss, $\partial W^{B S} / \partial \tau$, corresponds very closely to that derived by Bulow and Summers. ${ }^{24}$ As they emphasized, the final term in equation (13a), describing the effects of uncertainty, should increase the measure of the efficiency cost of a tax increase - when asset prices go up, consumption also goes up, so $U_{1}^{\prime}$ goes down.

However, if we compare equation (13a) with equation (13), we see that when additional periods are added, the total welfare loss from a tax increase is not the discounted sum of

24 They omit the second term in this equation, as do most writers. 
expressions such as appear in equation (13a). The nonstochastic terms in the two equations do correspond, but the last term in each equation, describing the effects of uncertainty, do not. Each covariance in equation (13) can be reexpressed, given the definition of $N_{t}$, as

$$
\beta^{s} \operatorname{cov}\left(U_{s}^{\prime}, q_{s}^{\prime} \frac{\partial N_{s}}{\partial \tau}\right)=\beta^{s} \operatorname{cov}\left(U_{s}^{\prime}, q_{s}^{\prime} \frac{\partial K_{s+1}}{\partial \tau}\right)-(1-\delta) \beta^{s} \operatorname{cov}\left(U_{s}^{\prime}, q_{s}^{\prime} \frac{\partial K_{s}}{\partial \tau}\right)
$$

Of these two terms, only the last appears in equation (13a). The first captures the effects of the same stochastic events on the value of the behavioral response in the following period. The sign of this first term should be positive, so serves to reduce the measure of the efficiency cost. The effects of the two terms therefore are opposite, and their absolute values should be similar. In fact, we argued above intuitively that the first term would likely be larger in absolute value. By focussing on only one period, Bulow and Summers omitted this first term, which depends on behavioral responses in the following period, and thereby substantially overestimated the welfare cost of a tax increase.

\section{Welfare costs of tax changes given economic depreciation}

Bulow-Summers also argue that granting firms economic depreciation for tax purposes, which would base depreciation deductions on the ex post change in the value of the firm's assets, will make new investment more attractive than allowing firms a deduction fixed ex ante based on the expected change in value of the firm's assets. This claim seems quite compelling since under economic depreciation the firm receives a form of coinsurance from the government at no expected cost. Under this coinsurance, the firm receives larger deductions and larger tax savings under those contingencies when the value of the firm's assets have declined more.

In order to explore this reasoning further, we derive the efficiency cost of changing the corporate tax rate when the tax bases depreciation deductions on the ex post change in value of the firm's assets, and compare the resulting measure with the efficiency costs which would arise instead when depreciation deductions are based on the ex ante expected decline in asset values. In doing so, we continue to assume (B1)-(B3), and also assume that the expected change in $q_{s}^{\prime}$ is zero at each date. Under these assumptions, the ex ante expected depreciation rate is $\delta$, and the present value of depreciation deductions of $\delta$ per cent of the remaining asset value each year would equal $\delta /(r+\delta)$. We will therefore compare the welfare costs as derived previously, assuming (B4) $z=\delta /(r+\delta)$, with those which would occur if the tax instead allowed economic depreciation.

With economic depreciation allowed in the tax law, the after-tax income of the firm in period $t$, denoted by $Y_{t}$, would equal $Y_{t} \equiv(1-\tau) \theta_{t} f\left(K_{t}\right)-\tau\left((1-\delta) q_{t}^{\prime}-q_{t-1}^{\prime}\right) K_{t}$. If bonds pay the fixed interest rate, $r$, each period, then the representative consumer's budget constraint in period $t$ now equals

$$
C_{t}=w_{t}+(1+r) B_{t-1}-B_{t}+Y_{t}-q\left(N_{t}\right)+L_{t} .
$$

The first-order conditions describing the optimal choices of $B_{t}$ and $N_{t}$ become

$$
U_{t}^{\prime}=(1+r) E_{t} U_{t+1}^{\prime}, \quad \text { and }
$$




$$
q_{t}^{\prime} U_{t}^{\prime}=E_{t} \sum_{s=t+1}^{\infty}(1-\delta)^{s-t-1}\left[(1-\tau) \theta_{s} f_{s}^{\prime}-\tau\left((1-\delta) q_{s}^{\prime}-q_{s-1}^{\prime}\right)\right] \beta^{s-t} U_{s}^{\prime}
$$

Proceeding as before, we find that the welfare cost of a permanent tax change, introduced in the initial period, satisfies:

Proposition 4: Given assumptions (B1)-(B3), the effect on welfare of a permanent increase in $\tau$ enacted in the initial period, given the use of economic depreciation, equals

$$
\frac{\partial W_{0}}{\partial \tau}=\left(\frac{\tau}{1-\tau}\right)\left(\frac{r}{1+r}\right) E_{0} \sum_{s=0}^{\infty} \frac{\partial N_{s}}{\partial \tau}\left(\sum_{t=s}^{\infty} q_{t}^{\prime} U_{t}^{\prime} \beta^{t}\right)(1-\delta)^{t-s}
$$

Proof: Differentiating $W$ with respect to $\tau$, and using the first-order conditions to eliminate any direct effects of behavioral responses, gives

$$
\frac{\partial W_{0}}{\partial \tau}=E_{0} \sum_{s=0}^{\infty} \frac{\partial N_{s}}{\partial \tau}\left[\tau \sum_{t=s+1}^{\infty}(1-\delta)^{t-s-1}\left(\theta_{t} f_{t}^{\prime}+q_{t}^{\prime}(1-\delta)-q_{t-1}^{\prime}\right) \beta^{t} U_{t}^{\prime}\right] .
$$

Using equation $\left(5 \mathrm{a}^{\prime}\right)$ to eliminate the terms with $\theta_{t} f_{t}^{\prime}$ and simslifying gives

$$
\frac{\partial W_{0}}{\partial \tau}=\frac{\tau}{1-\tau} E_{0} \sum_{s=0}^{\infty} \frac{\partial N_{s}}{\partial \tau}\left[\sum_{t=s}^{\infty} q_{t}^{\prime}\left(U_{t}^{\prime} \beta^{t}-U_{t+1}^{\prime} \beta^{t+1}\right)(1-\delta)^{t-s}\right] .
$$

But $E_{0}\left(\partial N_{s} / \partial \tau\right) q_{t}^{\prime}\left(U_{t}-U_{t+1}^{\prime}\right)=E_{0} E_{t}\left(\partial N_{s} / \partial \tau\right) q_{t}^{\prime}\left(U_{t}^{\prime}-U_{t+1}^{\prime}\right)$. But the only variable in this expression that is stochastic, given the information in period $t$, is $\beta^{t+1} U_{t+1}^{\prime}$, and its expectation is $\beta^{t} U_{t}^{\prime} /(1+r)$. Substituting this into equation (21) immediately gives the desired result.

When the tax law allows economic depreciation, the expression for the welfare loss from a tax increase looks much different. In order to compare the welfare losses that occur under the two alternative depreciation rules, it is helpful to prove the following result.

Corollary 3: Given assumptions (B1)-(B4), the effect on welfare of a permanent increase in $\tau$ enacted in the initial period, given the use of economic depreciation, also equals

$$
\begin{aligned}
\frac{\partial W_{0}}{\partial \tau}= & \frac{\tau(1-z)}{1-\tau} \sum_{s=0}^{\infty}\left[E_{0} q_{s}^{\prime} \frac{\partial N_{s}}{\partial \tau}(1+r)^{-s}+\beta^{s} \operatorname{cov}\left(U_{s}^{t}, q_{s}^{\prime} \frac{\partial N_{s}}{\partial \tau}\right)\right] \\
& +\left(\frac{\tau}{1-\tau}\right)\left(\frac{r}{1+r}\right) \sum_{s=0}^{\infty} \sum_{t=s}^{\infty}\left[E_{0}\left(q_{t}^{\prime}-q_{s}^{\prime}\right) \frac{\partial N_{s}}{\partial \tau} \frac{(1-\delta)^{t-s}}{(1+\tau)^{t}}\right. \\
& \left.+\beta^{t} \operatorname{cov}\left(U_{t}^{\prime},\left(q_{t}^{\prime}-q_{s}^{\prime}\right) \frac{\partial N_{s}}{\partial \tau}\right)(1-\delta)^{t-s}\right] .
\end{aligned}
$$

Proof: Substituting the identity $q_{t}^{\prime} U_{t}^{\prime}=\left[q_{s}^{\prime}+\left(q_{t}^{\prime}-q_{s}^{\prime}\right)\right]\left[E_{0} U_{t}^{\prime}+\left(U_{t}^{\prime}-E_{0} U_{t}^{\prime}\right)\right]$ into equation (19) and using equation $\left(4^{\prime}\right)$, quickly gives equation (22). 
If we compare the expressions in equations $(22) \approx n d(10)$, we find that the first line in equation (22) is identical in form to the right-hard side of equation (10). ${ }^{25}$ Shifting to economic depreciation results in the addition of the next two lines in equation (22) to the measure of the welfare cost of a tax change. But the second line is nonzero only if $E_{s} q_{t}^{\prime} \neq q_{s}^{\prime}$ for $t>s$. The rationale for this term was described above. The remaining term seems to capture quite directly the intuition of Bulow-Summers that economic depreciation is more favorable than depreciation deductions fixed ex ante based on the expected decline in asset value. Assuming that $q_{s}^{\prime} \partial N_{s} / \partial \tau$ is negative and nonstochastic, this term includes expressions of the form $\operatorname{cov}\left(\left(q_{t}^{\prime} / q_{s}^{\prime}-1\right), U_{t}^{\prime}\right)$, which is just the measure of the risk bearing cost arising from asset price variability. The presence of this extra term should lower the welfare cost of a tax increase. But under the assumption that $q_{s}^{\prime} \partial N_{s} / \partial \tau$ is nonstochastic, the last term in equation (10) is zero, and the welfare cost of tax changes given current depreciation iules, which specify depreciation deductions ex ante, would be correctly described by the measure $-\sum_{s} T_{s}^{n} E\left(\Delta X_{s}\right)$.

If $q_{s}^{t} \partial N_{s} / \partial \tau$ is stochastic, then in general it is difficult to sign the last term in equation (22). However, the following lemma provides some assistance:

Lemma 1 If $A, B$, and $C$, are random variables, and if (1) $A$ and $B$ are independent, (2) $\operatorname{cov}(B, C)>0$, (3) $\operatorname{cov}(A, C)<0$, and (4) $E(B)<0$, then $\operatorname{cov}(A B, C)>0$.

Proof: See the appendix.

In applying this lemma, let $A=\left(q_{t}^{\prime}-q_{s}^{\prime}\right) / q_{s}^{\prime}, B=q_{s}^{\prime} \partial N_{s} / \partial \tau$, and $C=U_{t}^{\prime}$. Then, assumption (4) of the lemma holds as long as the tax discourages investment, while assumption (3) holds as long as the representative individual is risk-averse with respect to the volatility in asset prices. Assumption (1) would normally not hold strictly, but if the expected change in asset prices is zero, given the information available at time $t$, then $\operatorname{cov}(A, B)=0$, so that $A$ and $B$ would be uncorrelated even if not independent. ${ }^{26}$ If we accept assumption (1) as a reasonable approximation, then the lemma says that if the second term in equation (22) is positive then the fourth term must also be positive, while the sign of the fourth term is ambiguous otherwise. Therefore, assumptions sufficient to ensure that this last term in equation (22) is positive, consistent with the Bulow-Summers intuition, should also imply that the second term in equation (10) is positive. ${ }^{27}$ In this case, the welfare cost of a tax increase given the existing depreciation rules would be overestimated using a measure of the form $-\sum_{s} T_{s}^{n} E\left(\Delta X_{s}\right)$.

${ }^{25}$ The functional forms are identical, but the numerical values of the endogenous variables will be different.

${ }^{26}$ Note that $E_{0} A B=E_{0} E_{t} A B$. But by its definition, $B$ is nonstochastic given the information available at time $t$, so $E_{0} E_{t} A B=E_{0} E_{t}(A) E_{t}(B)$. But if the expected change in asset prices is zero, then $E_{t} A=0$.

27 The qualification is that the tax changes being analyzed in equations (10) and (22) are different, and some assumptions may exist ensuring that the second term in equation (22) is positive without implying that the corresponding term in equation (10) is also positive. 


\section{Conclusions}

In this paper, we have derived a measure of the efficiency cost of taxing risky capital income in an infinite horizon stochastic model. The resulting measure differs from all those that have been proposed in the existing literature. We show that the resulting measure can be be represented by the expression $-\sum_{s} T_{s}^{n} c\left(\Delta X_{s}\right)$, where $T_{s}^{n}$ measures the present value of the taxes that would be paid on a unit of investment in a riskless project otherwise equivalent to $X_{s}$, while $c\left(\Delta X_{s}\right)$ represents the certainty equivalent to the representative individual of the lottery $\Delta X_{s}$. This change in the amount of future investment resulting from a tax change will be stochastic not only due to unexpected changes in the profitability of new investment but also due to unexpected changes in wealth. If $\Delta X_{s}$ were nonstochastic, then this measure reduces to the measure $-\sum_{s} T_{s}^{n} E\left(\Delta X_{8}\right)$ that has been used in a number of applied studies. ${ }^{28}$

In order to assess the complicating effects of risk on the measurement of the efficiency costs of tax changes, we must assess how $c\left(\Delta X_{s}\right)$ compares to $E\left(\Delta X_{s}\right)$. Unfortunately, this is difficult to do theoretically in an infinite horizon stochastic model. We argue both intuitively and by example that the correct measure of the efficiency cost of a tax change is likely to be smaller than that implied by the measure $-\sum_{s} T_{s}^{n} E\left(\Delta X_{s}\right)$, but firm conclusions must await further research.

We were unable to find support for the argument in Bulow-Summers(1984) that the efficiency cost of taxing risky capital income is much larger than that implied by measures of the form $-\sum_{s} T_{s}^{n} E\left(\Delta X_{s}\right)$ when the main risk in the return to new investment is from a random asset value. In particular, we show that the specific efficiency cost measure they propose omits terms appearing in our measure derived from an infinite horizon model which substantially reduce the measured efficiency cost. However, we do find some support for their argument that the efficiency cost of a corporate income tax would be less if the tax allows depreciation deductions to be based on the ex post change in asset values rather than the ex ante expected change in asset values. This comparison is clear, however, only under assumptions which imply that under the existing form of depreciation deductions, the efficiency cost of a tax change is overestimated by the expression $-\sum_{s} T_{s}^{n} E\left(\Delta X_{s}\right)$.

28 See, for example, Fullerton-Gordon(1983) and Slemrod(1983). 


\section{References}

Abel, Andrew. 1980. "Empirical Investment Equations: An Integrative Framework." Journal of Monetary Economics Supplement. 12: 39-91.

Auerbach, Alan J. 1983. "Corporate Taxation in the United States." Brookings Papers on Economic Activity: 451-506.

Bulow, Jeremy I. and Lawrence H. Summers. 1984. "The Taxation of Risky Assets." Journal of Political Economy 92: 20-39.

Feldstein, Martin S. 1978. "The Welfare Cost of Capital Income Taxation." Journal of Political Economy 86, no. 2: S29-S51.

Fullerton, Don and Roger H. Gordon. 1983. "A Reexamination of Tax Distortions in General Equilibrium Models." in Martin S. Feldstein, ed. Behavioral Simulation Methods in Tax Policy Analysis. Chicago: University of Chicago Press.

Fullerton, Don, Shoven, John, and John Whalley. 1978. "General Equilibrium Analysis of U.S. Taxation Policy." in Compendium of Tax Research. U.S. Treasury Department. Washington: U.S. Government Printing Office.

Galper, Harvey, Robert Lucke, and Eric Toder. 1985. "Taxation, Portfolio Choice, and the Allocation of Capital." Mimeo.

Gordon, Roger H. 1985a. "Taxation of Corporate Capital Income: Tax Revenues Versus Tax Distortions." Quarterly Journal of Economics 100: 1-27.

Hall, Robert E. and Dale W. Jorgenson. 1967. "Tax Policy and Investment Behavior." American Economic Review 57: 391-414.

Harberger, Arnold. 1971. "Three Basic Postulates For Applied Welfare Economics." Journal of Economic Literature 9: 785-797.

Hayashi, Fumio. 1982. "Tobin's Marginal and Average q: A Neoclassical Interpretation." Econometrica 50: 213-224.

Slemrod, Joel. 1983. "A General Equilibrium Model of Taxation with Endogenous Financial Behavior." in Martin S. Feldstein, ed. Behavioral Simulation Methods in Tax Policy Analysis. Chicago: University of Chicago Press.

Stiglitz, Joseph E. 1969. "Effects of Wealth, Income, and Capital Gains Taxation on Risk Taking." Quarterly Journal of Economics 83: 263-83.

Summers, Lawrence H. 1981. "Taxation and Corporate Investment: A $q$-Theory Approach." Brookings Papers on Economic Activity: 67-127.

Tobin, James. 1958. “Liquidity Preference as Behavior Towards Risk." Review of Economic Studies 25: 65-86. 


\section{APPENDIX}

\section{Proof of Propositions (2ab) and Lemma 1}

Proof of propositions (2ab): Given assumptions (A2)-(A4), the individual faces a budget constraint each period of $C_{t}=F_{t} K_{t}-K_{t+1}$, where $F_{t}=m \theta_{t}+\left(1-\delta_{t}\right)$. Given the utility function described in assumption (A1), the first-order conditions are $C_{t}^{-\gamma}=$ $\beta E_{t} F_{t+1}^{n} C_{t+1}^{-\gamma}$, where $F_{t}^{n}=m \theta_{t}(1-\tau) /(1-\tau z)+\left(1-\delta_{t}\right)$. Given assumption (A5), it is easy to show that these first-order conditions are satisfied when $K_{t+1}=\alpha F_{t} K_{t}$ and $C_{t}=$ $(1-\alpha) F_{t} K_{t}$. The parameter $\alpha$ is implicitly defined by the equation $\alpha^{\gamma}=\beta E_{t}\left(F_{t+1}^{n} / F_{t+1}\right)$, so does not depend on $t$ by the iid assumption. It follows trivially that $\partial \alpha / \partial \tau<0$.

In order to characterize the second term in equation (10), we must first characterize $\partial N_{t} / \partial \tau$. By definition, $N_{t}=K_{t+1}-\left(1-\delta_{t}\right) K_{t}=K_{t}\left(\alpha F_{t}-\left(1-\delta_{t}\right)\right)$. Differentiating with respect to $\tau$, we find that

$$
\frac{\partial N_{t}}{\partial \tau}=F_{t} K_{t} \frac{\partial \alpha}{\partial \tau}+\left(\alpha F_{t}-\left(1-\delta_{t}\right)\right) \frac{\partial K_{t}}{\partial \tau}
$$

But by backwards induction, $K_{t}=\alpha^{t}\left(\Pi_{i=1}^{t-1} F_{i}\right) F_{0} K_{0}$. Differentiating with respect to $\tau$ gives $\partial K_{t} / \partial \tau=\left(t K_{t} / \alpha\right)(\partial \alpha / \partial \tau)$. Substituting into equation (A1) gives

$$
\frac{\partial N_{t}}{\partial \tau}=\frac{K_{t}}{\alpha} \frac{\partial \alpha}{\partial \tau}\left[(t+1) \alpha m \theta_{t}+((t+1) \alpha-t)\left(1-\delta_{t}\right)\right] .
$$

Our objective is to sign the covariance of the term in equation (A2) with $U_{t}^{\prime}=[(1-$ $\left.\alpha) F_{t} K_{t}\right]^{-\gamma}$ given either assumptions (A6) or (A7). To do this, the following lemma is helpful.

Lemma A1: Let $\mathbf{x}$ be a vector of independent random variables, and let $f(x)$ and $g(x)$ be functions of these random variables. Then if the functions $f($.$) and g($.$) are everywhere$ increasing in $\mathbf{x}$, then $\operatorname{cov}(f(\mathbf{x}), \mathbf{g}(\mathbf{x})) \geq \mathbf{0}$.

Proof: Consider first the case in which there is only one random variable, and let $\bar{f}$ and $\bar{g}$ represent the expected values of these two functions over the distribution of this random variable. Each function by assumption is increasing in this random variable. Let $x^{M}$ represent the minimum value at which both values $f-\bar{f}$ and $g-\bar{g}$ are nonnegative. Assume without loss of generality that, as $x$ increases, $f-\bar{f}$ becomes nonnegative before $g-\bar{g}$. It then follows that $\operatorname{cov}(f, g)=\int(f-f)(g-\bar{g}) \geq\left(f\left(x^{M}\right)-f\right) \int(g-\bar{g})=0$. It is easy to verify that the inequality is satisfied point by point for all values of $x$.

If there are two random variables, $x_{1}$ and $x_{2}$, then the above argument can be applied to show that $\int\left[\int f g d x_{1}\right] d x_{2} \geq \int\left(\int f d x_{1}\right)\left(\int g d x_{1}\right) d x_{2}$. But each of the functions $\int f d x_{1}$ and $\int g d x_{1}$ is increasing in $x_{2}$, so the same argument can be reapplied to show that $\iint f g d x_{1} d x_{2} \geq f \bar{g}$. If $\mathbf{x}$ has dimension greater than 2 , the same argument can be applied iteratively to confirm that $\int f g d x \geq \bar{f} \bar{g}$, implying that $\operatorname{cov}(f, g) \geq 0$. 
As is seen in the above expressions, any stochastic events that occurred before period $t$ affect the covariance between $U_{t}^{\prime}$ and $\partial N_{t} / \partial \tau$ only through the value of $K_{t}$. But since any stochastic increase in $K_{t}$ lowers the algelraic values of both $U_{t}^{\prime}$ and $\partial N_{t} / \partial \tau$, as is seen in the above expressions, these past stochastic events create a positive covariance according to the lemma. Similarly, both $U_{t}^{\prime}$ and $\partial N_{t} / \partial \tau$ are negative functions of the current value of $\theta_{t}$, so this random disturhance also creates a positive covariance according to the lemma. Finally, $U_{t}^{\prime}$ is a positive function of $\delta_{t}$, and $\partial N_{t} / \partial \tau$ is also as long as $\alpha>t /(1+t)$. These results plus the lernma therefore prove Propositions (2ab).

Proof of Lemma 1: By definition,

$$
\operatorname{cov}(A B, C)=\int_{A B C} A B C f(A, B, C)-E(A B) E(C),
$$

where $f(A, B, C)$ is the joint probability distribution of $A, B$, and $C$. Since $A$ and $B$ are independent, we know that $E(A B)=E(A) E(B)$ and that $f(A, B, C)=g(A, C) h(B, C)$, for some probability distributions $g(A, C)$ and $h(B, C)$. Therefore,

$$
\operatorname{cov}(A B, C)=\int_{A C} A C g(A, C) \int_{B} B h(B, C)-E(A) E(B) E(C) .
$$

But $\int_{B} B h(B, C)=E(B \mid C)=E(B C) / E(C)$. Since, by assumption, $\operatorname{cov}(B, C)>0$, it follows that $E(B C) / E(C)>E(B)$. Therefore,

$$
\operatorname{cov}(A B, C)>E(B)\left[\int A C g(A, C)-E(A) E(C)\right]=E(B) \operatorname{cov}(A, C) \text {. }
$$

By assumptions (3) and (4) of the lemma, we can then $\operatorname{conclude}$ that $\operatorname{cov}(A B, C)>0$. 